(C2009. This manuscript version is made available under the CC-BY-NC-ND 4.0 license http://creativecommons.org/licenses/by-nc-nd/4.0/

\title{
Study of thermoelectric systems applied to electric power generation
}

\author{
A. Rodríguez, J.G. Vián, D. Astrain, A. Martínez \\ Dpto. Ingeniería Mecánica, Energética y de Materiales. Universidad Pública de Navarra, Pamplona, \\ Spain \\ Tel. +34 948169309, e-mail: vian@unavarra.es
}

\begin{abstract}
A computational model has been developed in order to simulate the thermal and electric behaviour of the thermoelectric generators. This model solves the non linear system of equations of the thermoelectric and heat transfer equations. The inputs of the program are the thermoelectric parameters as a function of the temperature and the boundary conditions, (room temperature and residual heat flux). The outputs are the temperature values of all the elements forming the thermoelectric generator, (performance, electric power, voltage and electric current generated). The model solves the equation system using the finite difference method and semi-empiric expressions for the convection coefficients.

It has been built a thermoelectric electric power generation test bench in order to validate and determine the accuracy of the computational model, which maximum error is lower than $5 \%$.

The objective of this study is to create a design tool that allows us to solve the system of equations involved in the electric generation process without needing to impose boundary conditions that are not known in the design phase, as the temperature of the Peltier modules.

With the computational model we study the influence of the heat flux supplied as well as the room temperature in the electric power generated.
\end{abstract}

Keywords: Thermoelectric; Power generation; Heat transfer; Computational model; Residual heat

\section{Nomenclature}

$\begin{array}{lll}A & \text { Area } & \left(\mathrm{m}^{2}\right) \\ C & \text { Thermal capacity } & \left(\mathrm{J} \mathrm{K} \mathrm{K}^{-1}\right) \\ c & \text { Specific heat } & \left(\mathrm{J} \mathrm{kg}^{-1} \mathrm{~K}^{-1}\right) \\ \mathrm{E}_{\mathrm{t}} & \text { Electromotive force } & (\mathrm{N}) \\ I & \text { Electric current } & (\mathrm{A}) \\ k & \text { Thermal conductivity } & \left.(\mathrm{W} \mathrm{m})^{-1} \mathrm{~K}^{-1}\right) \\ L & \text { Characteristic length } & (\mathrm{m}) \\ m & \text { Load ratio } & \left(\mathrm{R}_{\mathrm{L}} / \mathrm{R}_{\mathrm{O}}\right) \\ N & \text { Number of thermocouples of Peltier modules } & \\ P & \text { Generated power } & (\mathrm{W}) \\ \dot{Q} & \text { Calorific power } & (\mathrm{W}) \\ * & \text { Calorific power per volume unity } & \left.(\mathrm{W} \mathrm{m})^{-3}\right) \\ q & \text { Thermal resistance } & (\mathrm{K} \mathrm{W}) \\ R & \text { Contact electric resistance } & (\mathrm{Ohm}) \\ R_{\text {cont }} & & \end{array}$




$\begin{array}{lll}R_{O} & \text { Electric resistance of the Peltier module } & (\mathrm{Ohm}) \\ R_{L} & \text { Load electric resistance } & (\mathrm{Ohm}) \\ T & \text { Temperature } & \left({ }^{\circ} \mathrm{C}\right) \\ T & \text { Temperature } & (\mathrm{K}) \\ T^{\prime} & \text { Temperature in next time step } & (\mathrm{K}) \\ V & \text { Volume } & \left(\mathrm{m}^{3}\right)\end{array}$

\section{Greek letters}

$\alpha \quad$ Seebeck Coefficient

$\Delta V \quad$ Difference of electric power

$\Delta T \quad$ Difference of temperatures

$\varepsilon \quad$ Test

$\rho \quad$ Density

$\rho_{0} \quad$ Electric resistance of the Peltier module

thom Thomson Coefficient

$\tau \quad$ Time
$(\mathrm{V} / \mathrm{K})$

(V)

(K)

$\left(\mathrm{kg} \mathrm{m}^{-3}\right)$

(Ohm m)

$\left(\mathrm{V} \mathrm{K}^{-1}\right)$

(s)

\section{Superscripts, subscripts}

c Cold side of the Peltier module

cont Semiconductor and copper contact

Dissip Dissipater

$\mathrm{h} \quad$ Hot side of the Peltier module

i Node $\mathrm{i}$

in System inlet

$\mathrm{k} \quad$ Number of Test $\varepsilon$ repetitions

J Joule effect

$\mathrm{j} \quad$ Node $\mathrm{j}$

leaks System loses

max Maximum value of the studied curve

out System outlet

re Electric resistance of generation of the heat flux

relat Relative

room Ambient 


\section{Introduction}

We have developed a computational model which simulates the thermal and electric behavior of a thermoelectric generator which presents some advantages respect previous ones.

Some applications in thermoelectric generation use waste heat fluxes as energy source. Benson et al [1] investigated geothermal heat fluxes with temperature gaps of $80-180^{\circ} \mathrm{C}$; other ones are produced in ocean's currents, in solar panels, or in power generator stations. Matsuura and Rowe [2] propose these and other residual thermal energy sources.

In order to study these applications is necessary to determine the behavior of the thermoelectric devices. The analytic solution more used to solve the equation system of the thermoelectric device is the ideal thermoelectric couple, which expression was obtained by Ioffe A.F. in [3]. Another references that use this expression were [4] and [5], and in the case of thermoelectric generation it was used in references [6], [7], [8], [9], [10] y [11]. In the expression of ideal thermoelectric couple the thermoelectric parameters (Seebeck coefficient, electrical resistivity and thermal conductivity) are not dependent on the temperature.

A better approximation is to consider an average value of the Seebeck coefficient within the operation temperatures of thermoelectric couple, as it can be seen in the research of Ioffe A.F. in [3], Arenas, A in [12] and Yu G. in [13]. Nevertheless, this approximation does not adjust to reality because in fact the Seebeck coefficient varies with the temperature. 
The Buist, R.J. works [14], [15] divides a thermoelement in segments and applies the ideal thermoelectric couple in each segment. This model keeps in mind the variation of the thermoelectric properties with the temperature. Its major disadvantage is that the model needs the heat flux, the hot source temperature and the electric current generated as input parameters and it is necessary to obtain them experimentally.

To determine completely the thermoelectric device behavior is also necessary to consider the heat exchangers on the sides of the Peltier module, as it is described by Stockholm, J. G. in [16]. The disadvantage of Stockholm's model is that simplifies the Peltier module and it is impossible to optimize the geometry and dimensions. Similar but more comprehensive models have been posed by Arenas in [12] and by Kondraitev in [17], but these models do not calculate the transitory state.

Our model is based in a computational model developed to simulate the behavior of thermoelectric refrigerators by Vián and Astrain [18], [19] and [20].

Our model solves the behaviour of thermoelectric generator and makes improvements to the previous models. It takes into account the properties of the thermoelectric materials as function of the temperature. We divide the Peltier module in ten different parts which allows us to determine the variation of the thermoelectric properties in its interior. The Thomson effect is considered not negligible which gives an approximation closer to the reality. The model inputs are only the room temperature and the heat flux supplied by the residual energy source, it is not necessary to obtain parameters experimentally.

The heat exchangers of the hot and cold side are included in our model; therefore can obtain as outputs the temperatures and the heat fluxes in all the components of the 
thermoelectric system. Another advantage is that our model determines the transitory state as well as to determine the steady state.

\section{Objectives}

The objectives we have proposed are:

- A computational model design capable to simulate the thermoelectric generator operation, including the heat transfer from the thermal sources until to the faces of the Peltier module. We will keep in mind the Thompson coefficient and all the thermoelectric properties will be a function of the temperature.

- Validation of the computational model with experimental data obtained from the test bench.

- Theoretical and experimental study of the influence in the thermoelectric power generated of the following parameters:

> Residual heat flux and electric load resistance for a constant room temperature.

$>$ Room temperature and electric load resistance for a constant residual heat flux.

$>$ Room temperature and electric load resistance for a constant temperature gap between the faces of the Peltier module.

\section{Computational Model}

In thermoelectric devices, for both refrigeration and generation applications, the temperatures in the faces of the Peltier modules and in the internal nodes can not be 
determined analytically without knowing the heat flux due to the thermoelectric effects. The system of equations in order to calculate the temperatures is non linear.

The model solves these non linear systems, formed by the thermoelectricity equations and the heat transfer ones, by the finite difference method, which calculates the temperature in different points separated in the space by a discrete distance. In the transient state the temperatures of these points are calculated in discrete periods of time. With this purpose a finite period of time is chosen and the temperatures for all the points are recalculated at the end of this time interval.

While solving the model using the implicit finite difference method the values of the heat flux can be determined using the values of the temperatures of the time step before.

The inputs of the model are: the geometric data and material properties of the elements of the thermoelectric system studied (thermal conductivity, electric resistivity, Seebeck coefficient and specific heat), and the thermal energy value supplied to the system. After the simulation, the outputs of the model are: the values of efficiency, electric voltage and current, electric power generated, temperatures and heat flux generated.

Previous works showed in references from [3] to [13], needed as inputs for their models, the temperature values on the Peltier module faces. These were experimentally measured in the thermoelectric generation system for each heat flux supplied.

Our model can determine all heat fluxes and temperatures of thermoelectric generator components only with the heat flux supplied by the residual energy source and the room temperature as inputs. This model no needs previous experimental values of ice-maker temperatures. 


\subsection{Hypothesis of the model}

The materials used in the test bench shown in Fig. 2 are considered isotropous.

The model has been built neglecting the magnetic field effects, so Hall, Nernst, Ettingshausen and Righi-Ludec effects are neglected as well.

\subsection{Equations of the model.}

The model solves the equation of the heat transfer in transitory state for one dimension and one-dimensional flow:

$$
\rho c_{p} \delta t / \delta \tau=k\left(\delta^{2} t / \delta x^{2}\right)+q^{*}
$$

The equation of the heat conduction (1) multiplied by the volume, applied to the i node as a function of the thermal resistances and capacities is:

$$
\left(T_{i-1}{ }^{\prime}-T_{i}{ }^{\prime}\right) / R_{i-1, i}+\left(T_{j}{ }^{\prime}-T_{i}{ }^{\prime}\right) / R_{i, j}+\dot{Q}_{i}=\left(T_{i}{ }^{\prime}-T_{i}\right) C_{i} / \delta \tau
$$

The generation or absorption of heat related to node $\mathrm{i}$ is represented by $\dot{Q}_{i}$ and its expression is given by equations (6) to (9).

The thermal resistance between nodes i and j, eq. (3) and the thermal capacity of node i, eq. (4) are:

$$
\begin{aligned}
& R_{i, j}=L_{i j} /\left(k_{i} A_{i}\right) \\
& C_{i}=V_{i} \rho_{i} c_{p}
\end{aligned}
$$

Therefore, the thermal resistance and capacity of the Peltier module is studied as done in [18]; in our case, we divide the module in ten nodes and we get a thermal resistance between nodes and a thermal capacity associated to each node as a function of its temperature. 
For the contact resistances between the elements of the test bench, the works of Ritzer and Lau [21] were used.

The thermal resistance and capacity of the Heat Extender are calculated using the equations (3) and (4) giving the following values:

$$
\begin{array}{ll}
R_{\text {Heat Extender }}=0.1677 & {[\mathrm{~K} / \mathrm{W}]} \\
C_{\text {Heat Extender }}=211 & {[\mathrm{~J} / \mathrm{kgK}]}
\end{array}
$$

In our case the thermal resistance of the dissipater and the insulator related to the ambient are calculated experimentally as described below:

Grouping the equation parameters as function of node temperatures and the heat flux we obtain the equation:

$$
-T_{i-1}{ }^{\prime} \delta \tau /\left(C_{i} R_{i-1, i}\right)+T_{i}\left[\delta \tau / C_{i}\left(1 / R_{i-1, i}+1 / R_{i, j}\right)+1\right]-T_{j}^{\prime} \delta \tau / C_{i} R_{i, j}=T_{i}+\dot{Q}_{i} \delta \tau / C_{i}
$$

The model incorporates the equations from the thermoelectric effects. These effects are the heat flux from the Peltier effects equations (6) and (7), Joule eq. (8), and Thomson eq. (9), with no magnetic fields.

$$
\begin{aligned}
& \dot{Q}_{h}=-N 2 \alpha_{h} I T_{h}+I^{2} R_{\text {cont }} \\
& \dot{Q}_{c}=N 2 \alpha_{c} I T_{c}+I^{2} R_{\text {cont }} \\
& \dot{Q}_{J}=I^{2} R_{0}=N I^{2} 2 \rho L / A \\
& \dot{Q}_{\tau}=\tau I \Delta T
\end{aligned}
$$


The temperature difference between the semiconductor terminals is used to calculate the heat fluxes due to the Peltier effect. The contribution of the contact thermal effects was developed in [2].

The discretization of the thermoelectric generator uses symbols of an electric analogy, shown in Fig. 1. The model assigns different nodes to the Peltier module in the ceramic part and in the end of the semiconductor, and thus, it is not necessary to correct the temperature gap between them. This is an improvement to the analytic solution of [2] which is necessary when only the experimental temperature of the ceramic part of the Peltier module is available. 


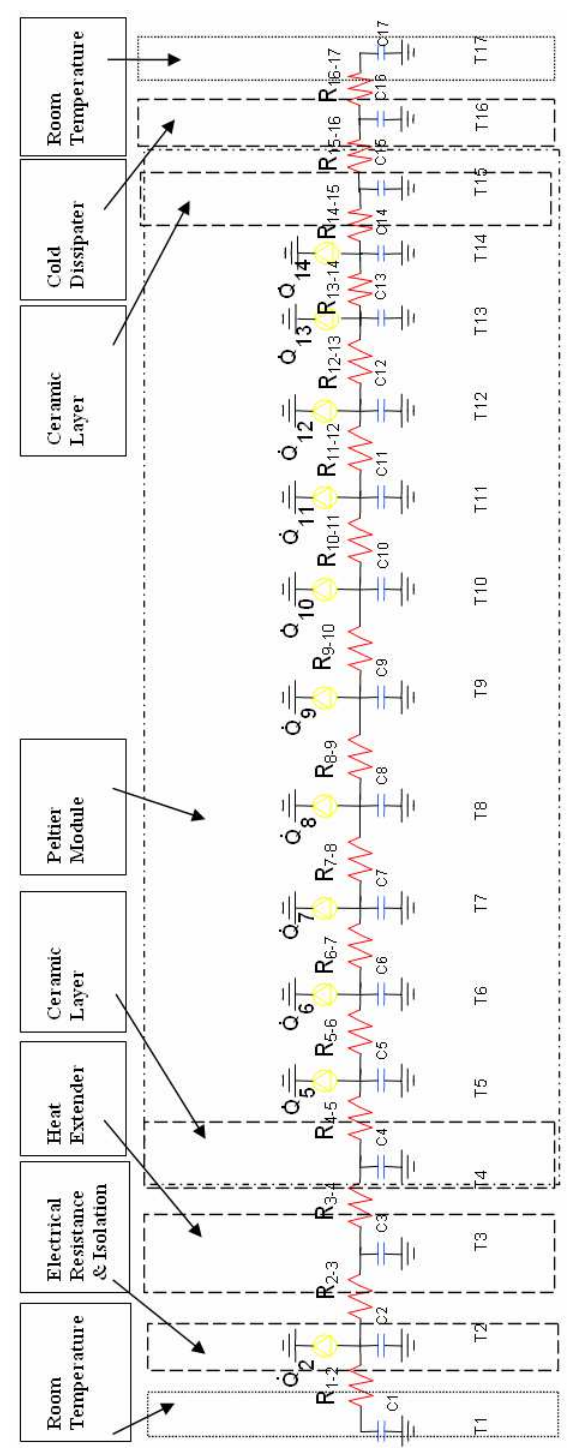

Fig. 1. Scheme of the thermal-electric analogy of the computational model.

With the scheme shown in Fig. 1 and the expression (5), we obtain the following system of equations:

$$
[M]\left[T_{i}^{\prime}\right]=\left[T_{i}\right]+\partial \tau / C_{i}\left[\dot{Q}_{i}\right]
$$

The matrix system (10) is developed as a function of the thermal resistances and capacities of the device, as shown in (11): 


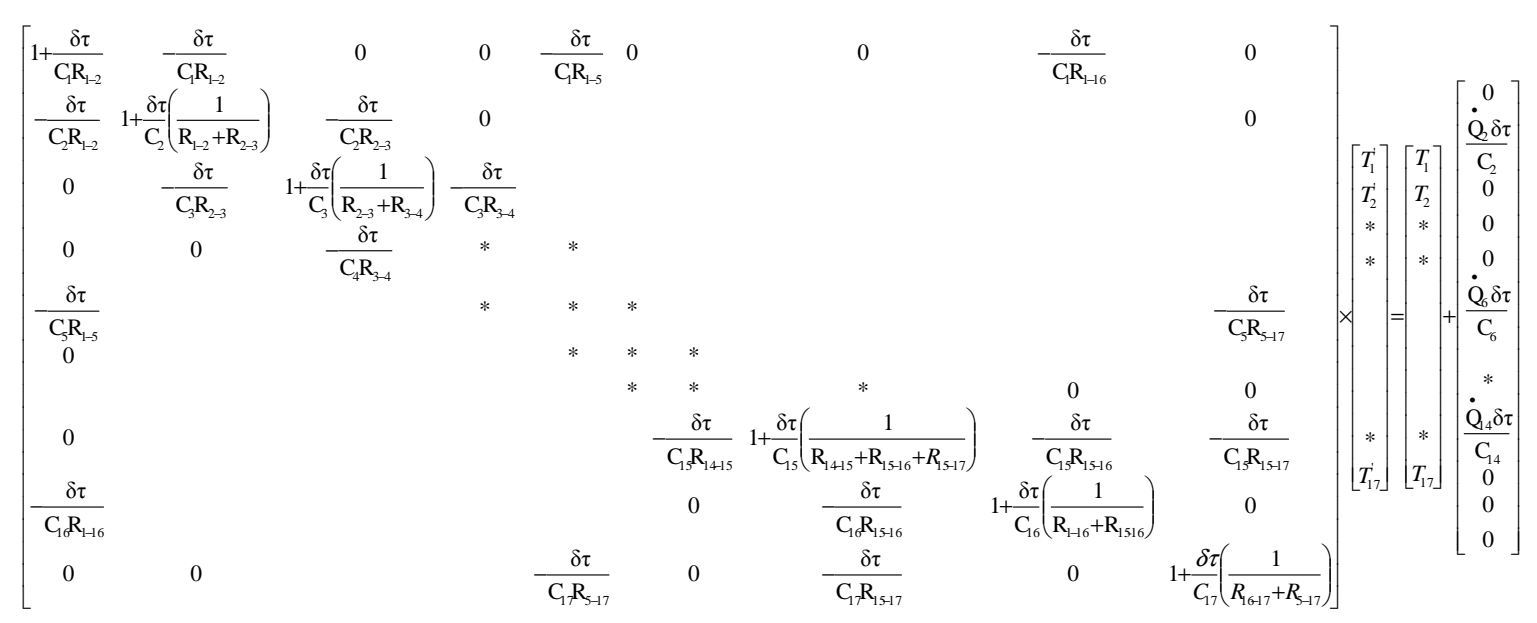

The Seebeck coefficient is a parameter variable with the temperatures, so if it is included in the model as a function of the temperature, we get the following expressions for the electromotive force generated due to the Seebeck effect, the voltage in the ends of the generator, the current and the electric power.

$$
\begin{aligned}
& E_{t}=2 N\left(\left(\alpha_{h} T_{h}-\alpha_{c} T_{c}\right)-\sum_{i=1}^{10} \tau_{i}\left(T_{i}-T_{i+1}\right)\right) \\
& \Delta V=(m / 1+m) E_{t} \\
& I=E_{t} /(1+m) R_{0} \\
& P_{\text {out }}=\Delta V I
\end{aligned}
$$

\section{Experimental work}

The assembly of the test bench, Fig. 2, has been designed for this work and it is composed by: 
- A calibrated electric resistance that simulates the thermal energy source, providing a heat flux $\dot{Q}$ er with a maximum value of $50 \mathrm{~W}$.

- A heat extender, with a known thermal resistance that communicates the electric resistance with the Peltier module.

- A Peltier module Marlow DT12-6L type.

- A dissipater for the cold side of the Peltier module, with a thermal resistance experimentally determined.

- A decade box CAM METRIC R420 in order to be able to simulate with different load resistances.

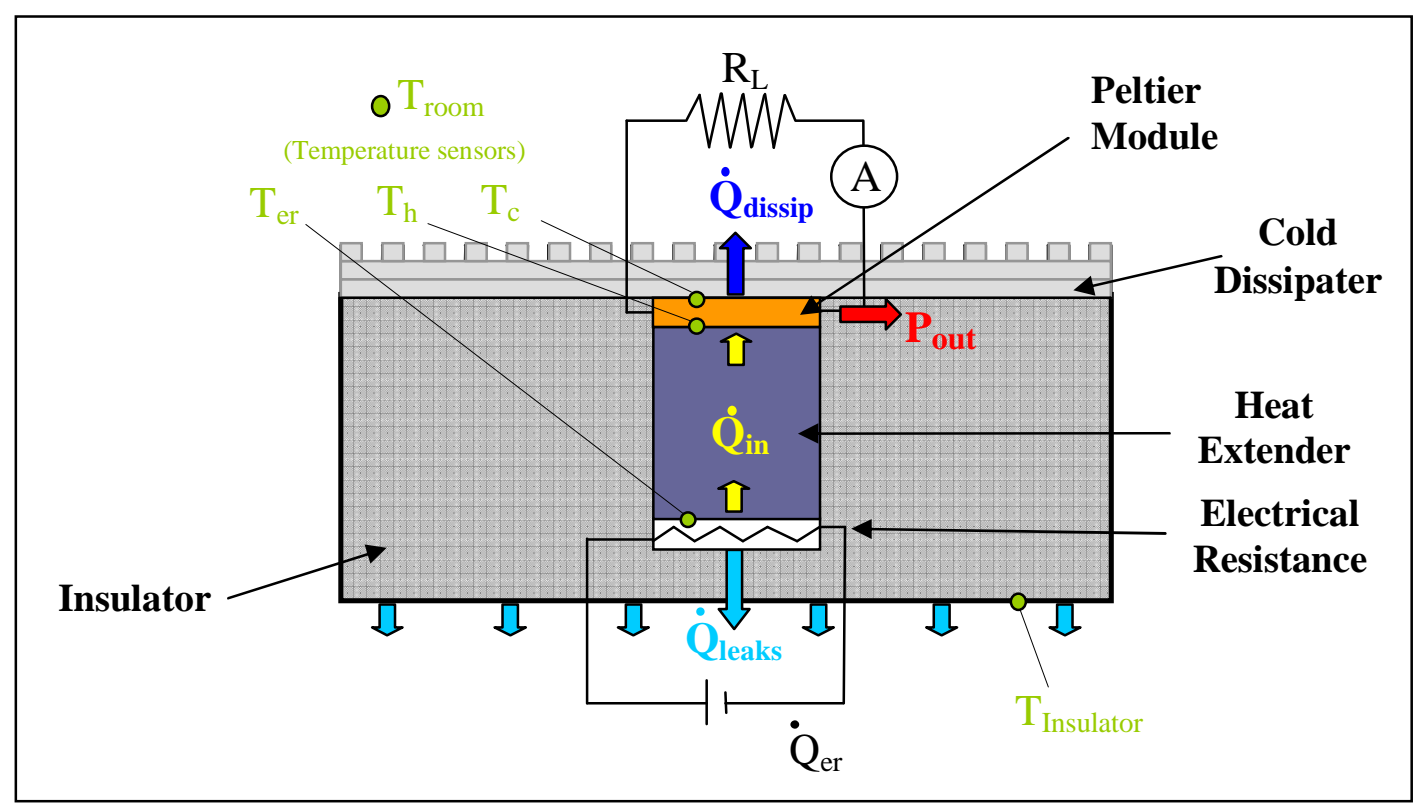

Fig. 2. Scheme of the test bench.

The principal element of study is the Peltier module Marlow DT12-6L, used generally in thermoelectric refrigeration. We have chosen this module to take advantage of residual 
thermal energies of low temperature, (lower than $85^{\circ} \mathrm{C}$ ), as its temperature range is the most suitable.

In order to determinate with accuracy the thermal resistance of the dissipater, we made some tests in a standardized climatic room. The tests were made with a prototype that used a known heat flux that went through the dissipater with the same temperature room conditions than the thermoelectric generator.

In Fig. 2 it can be seen the heat flux that goes through the heat extender is the same than the heat absorbed by the Peltier module $\dot{Q}_{\text {in }}$. This is calculated with the temperature gap between the ends of the heat extender and the thermal resistance of the heat extender, using the expression (16).

$$
\dot{Q}_{\text {in }}=\Delta T_{\text {Heat Extender }} / R_{\text {Heat Extender }}
$$

In an open circuit case, $\left(\mathrm{R}_{\mathrm{L}}=0\right)$, there is no Peltier effect and thus, there is no electric power generated in the Peltier module $\left(\mathrm{P}_{\text {out }}=0\right)$, so the heat flux absorbed is $\dot{Q}_{\text {in }}$, and fits in with the flux through the dissipater $\dot{Q}_{\text {Dissip }}$; With this data and experimentally measuring the temperature gap between the dissipater and the ambient, we determined the thermal resistance of the dissipater using the expression (17).

$$
R_{\text {Dissip }}=\Delta T_{\text {Dissip-Ambient }} / Q_{\text {Dissip }}
$$

In Table 1 the values of the thermal resistance for different heat fluxes of the dissipater $\dot{Q}_{\text {Dissip }}$ are shown. The data of the thermal resistance of the dissipater are independent of the thermoelectric device installed and the thermal resistance of the dissipater is an input data for the model. 
Table 1.

Thermal resistance of the dissipater.

\begin{tabular}{ccc}
\hline$\dot{Q}$ Dissip. & $\Delta \mathrm{T}_{\text {Dissip-Ambient }}$ & $\mathrm{R}_{\text {Dissip }}$ \\
{$[\mathrm{W}]$} & {$[\mathrm{K}]$} & {$[\mathrm{K} / \mathrm{W}]$} \\
25,93 & 21,8 & 0,84 \\
21,54 & 18,1 & 0,84 \\
18,35 & 15,2 & 0,83 \\
13,96 & 11,4 & 0,82 \\
9,17 & 7,6 & 0,83 \\
4,39 & 3,7 & 0,84 \\
\hline
\end{tabular}

The temperature probes are thermocouples $\mathrm{K}$ type and the data logging is ALMEMO 5590-2. A thermocouple is placed in each point of study shown in Fig. 2. The tests were placed in a climatic room CLIMATS $1440 \mathrm{H}$ 60/3 to keep the room temperature constant.

The heat flux due to the leaks eq. (19) is the difference between the heat fluxes generated by the electric resistance eq. (18) minus the absorbed by the Peltier module eq. (16).

$$
\begin{aligned}
& \dot{Q}_{e r}=\Delta V_{e r} I_{e r} \\
& \dot{Q}_{\text {leaks }}=\dot{Q}_{e r}-\dot{Q}_{i n}
\end{aligned}
$$

The thermal resistance between the electric resistance and the ambient is determined using the same methodology that we used to calculate the thermal resistance of the dissipater, using two thermocouples placed in the ambient and tin the electric resistance. Then the temperature gap between the electric resistance and the ambient is known. Thus, with the value of the heat flux that is transmitted we calculate the thermal resistance as is shown in Table 2 for different values of the income flux.

\section{Table 2.}

Thermal resistance between the thermal generator source and the room. 


\begin{tabular}{rcccc}
\hline$\dot{Q}_{e r}[\mathrm{~W}]$ & $\dot{Q}_{\text {in }}[\mathrm{W}]$ & $\dot{Q}_{\text {leaks }}[\mathrm{W}]$ & $\Delta \mathrm{T}_{\text {Electr.Resist-Ambient }}[\mathrm{K}]$ & $\mathrm{R}_{\text {Electr.Resist-Ambient }}[\mathrm{K} / \mathrm{W}]$ \\
29,7 & 25,9 & 3,8 & 76,2 & 20,1 \\
24,5 & 21,5 & 2,9 & 65,7 & 22,4 \\
21,0 & 18,4 & 2,7 & 56,7 & 21,4 \\
15,4 & 14,0 & 1,4 & 34,6 & 24,7 \\
10,3 & 9,2 & 1,1 & 25,7 & 23,4 \\
5,1 & 4,4 & 0,7 & 13,8 & 20,0 \\
\hline
\end{tabular}

In order to study the electric power generated, it is necessary to keep in mind the load resistance of the device joint to the thermoelectric generator. To simulate this load resistance a decade box has been used, CAM METRIC R420, which provides a variable resistance from $0.01 \Omega$ to $100 \Omega$.

\section{Results and discussion.}

The experimental data obtained from the test bench are compared with the values from the computational model. With this comparison we make a validation of the model to determine the error between the experimental and the simulated values.

The sample mean $\bar{P}_{\text {out, } \varepsilon}$ of the measurement results is estimated from 10 independent observation of $\mathrm{P}_{\varepsilon}$ obtained under the same conditions of measurement.

$$
\bar{P}_{o u t, \varepsilon}=\frac{1}{n} \sum_{k=1}^{10} P_{o u t, \varepsilon, k}
$$

The standard uncertainty $\mathrm{u}\left(\mathrm{P}_{\mathrm{out}, \varepsilon}\right)$ associated with $\bar{P}_{\text {out }, \varepsilon}$ is the estimated standard deviation of the mean, given by the expression.

$$
u\left(P_{o u t, \varepsilon}\right)=\left(\frac{1}{n(n-1)} \sum_{k=1}^{10}\left(P_{o u t, \varepsilon, k}-\bar{P}_{o u t, \varepsilon}\right)^{2}\right)^{1 / 2}
$$

Therefore, the relative uncertainty of the experimental measurement is estimated as follows: 


$$
u_{\text {relat }}\left(P_{\text {out }, \varepsilon}\right)=\frac{u\left(P_{\text {out }, \varepsilon}\right)}{\bar{P}_{\text {out }, \varepsilon}}
$$

The total relative uncertainty of the experiments was acceptable. It was lower than $1.5 \%$ in the case of output power and lower than $2 \%$ in the case of temperatures.

In order to study the output power of the thermoelectric generator system we have analyzed three different cases:

I) Constant room temperature, varying the residual heat flux and the load electric resistance.

II) Constant residual heat flux, varying the room temperature and the load electric resistance.

III) Constant temperature gap between the Peltier module, varying the room temperature and the load electric resistance.

The model we present in this work can determine the temperatures and heat fluxes of all nodes of the thermoelectric generation system components. It only needs as input, the heat flux supplied to the hot source and room temperature. It is not necessary to know previously the electric current as in [16], or [17]. In our case, the current is not an input parameter but an output parameter related with all the unknowns by the eq. (14); moreover, it uses the thermoelectric parameters as a function of the temperature.

\subsection{Case I: Constant room temperature varying the residual heat flux and the load electric resistance.}

\subsubsection{Computational model validation}


In the tests developed for the present case the heat flux was constant. This heat flux simulates the residual thermal energy. The electric power obtained is measured for each of the load resistances tested.

In Fig. 3 and Fig. 4 is shown a comparison of the model and experimental values for residual heat flux of $\dot{Q}_{i n}=5 \mathrm{~W}$ and $\dot{Q}_{\text {in }}=30 \mathrm{~W}$. The values are acceptable with an error lower than the $5 \%$.

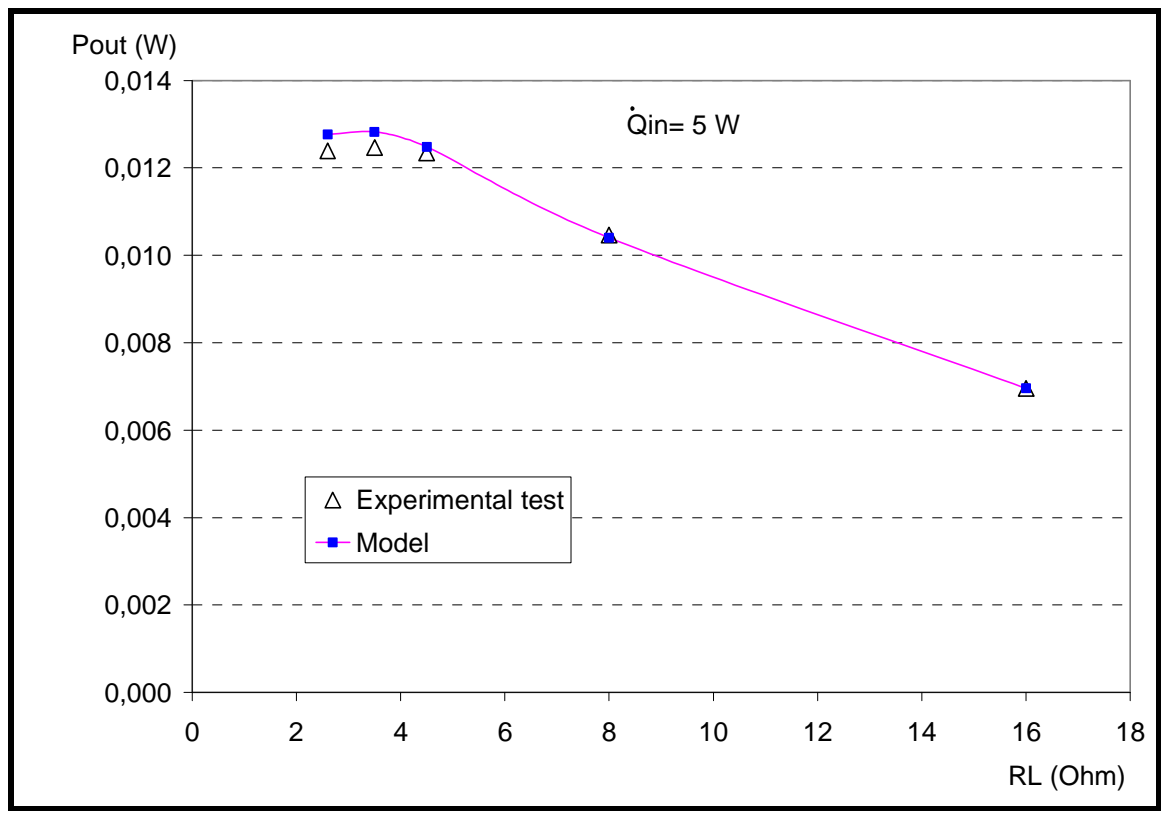

Fig. 3. Comparison of the power generated from the model and the experimental data for a heat flux of $5 \mathrm{~W}$. 


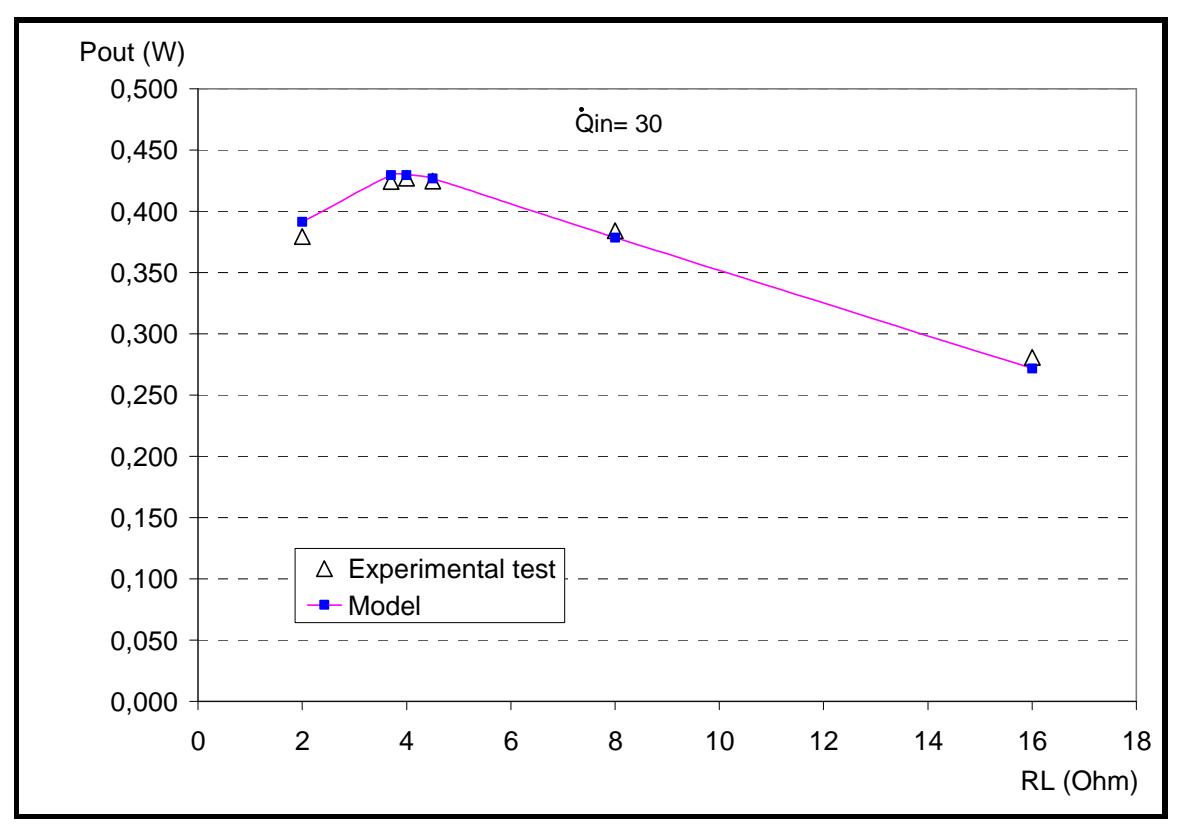

Fig. 4. Comparison of the electric power generated by the model and experimental data for a supplied heat flux of $30 \mathrm{~W}$.

The maximum electric power is produced for values of load resistance equal to the internal resistance of the Peltier module. This behavior was demonstrated analytically in reference [2]. For a constant room temperature, the greater is the supplied residual heat flux, the higher the temperature of the Peltier module is.

\subsubsection{Output thermoelectric power experimental and simulated}

Our model has into account the variation of the electric resistance of the Peltier module with the temperature. Thus the load electric resistance that gives the maximum power increases, with the temperature, as internal electric resistance of the Peltier module increases with the temperature as well. As an example, it can be seen that if a heat flux of $30 \mathrm{~W}$ is supplied, the load resistance value for the maximum power generated is $3.9 \Omega$ and 
if the heat flux has a value of $5 \mathrm{~W}$ the load resistance increases to $3.3 \Omega$ what makes a rise of the $18 \%$. This effect is shown in Fig. 5.

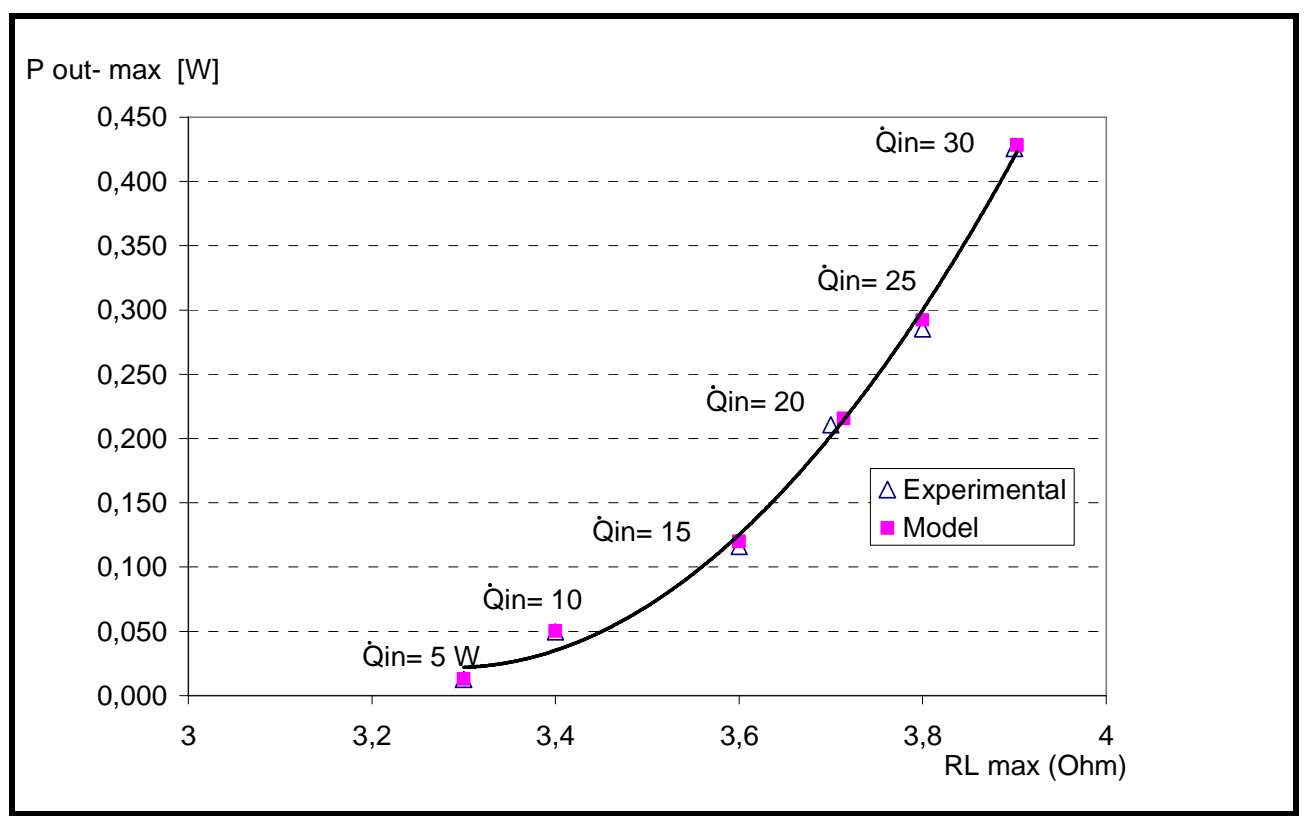

Fig. 5. Thermoelectric generated power maximum for each curve of heat flux constant with a room temperature of Troom $=273 \mathrm{~K}$.

With the analytical solution of ideal thermoelectric couple developed from references [3] to [11] or in the models that use average values of the thermoelectric parameters, references [12] and [13], the power and efficiency curves are calculated as a function of the electric current generated, keeping constant the temperature gap between the faces of the Peltier module.

With the models of the mentioned works it is not possible to determine the effect shown in Fig 5. As a matter of fact, increasing the supplied heat flux, the absorbed heat due to the Peltier effect increases. Thus the temperature gap between the Peltier module's faces increases. In case of the works from references [3] to [11] it would be necessary to calculate 
experimentally the temperature of the faces of the Peltier module each time the heat flux varies, in order to determine the generated thermoelectric power.

\subsubsection{Temperature gap between the sides of the Peltier module experimental and simulated.}

The model calculates the temperatures and the heat fluxes of all the elements of the thermoelectric device. As it can be seen in Fig. 6, for a constant heat flux supplied, when the load resistance $R_{L}$ increases then the temperature gap between the faces of the Peltier module increases $(\Delta \mathrm{T})$ too. The simulation results with the model have very good accuracy with errors lower than the $5 \%$ with the experimental results. As an example, let's see what happens for a supplied heat flux of $30 \mathrm{~W}$ where the temperature gap between the faces of the Peltier module increases $10 \mathrm{~K}$ (what makes an increase of 27\%) when the load resistance is varied from $2 \Omega$ to $16 \Omega$. 


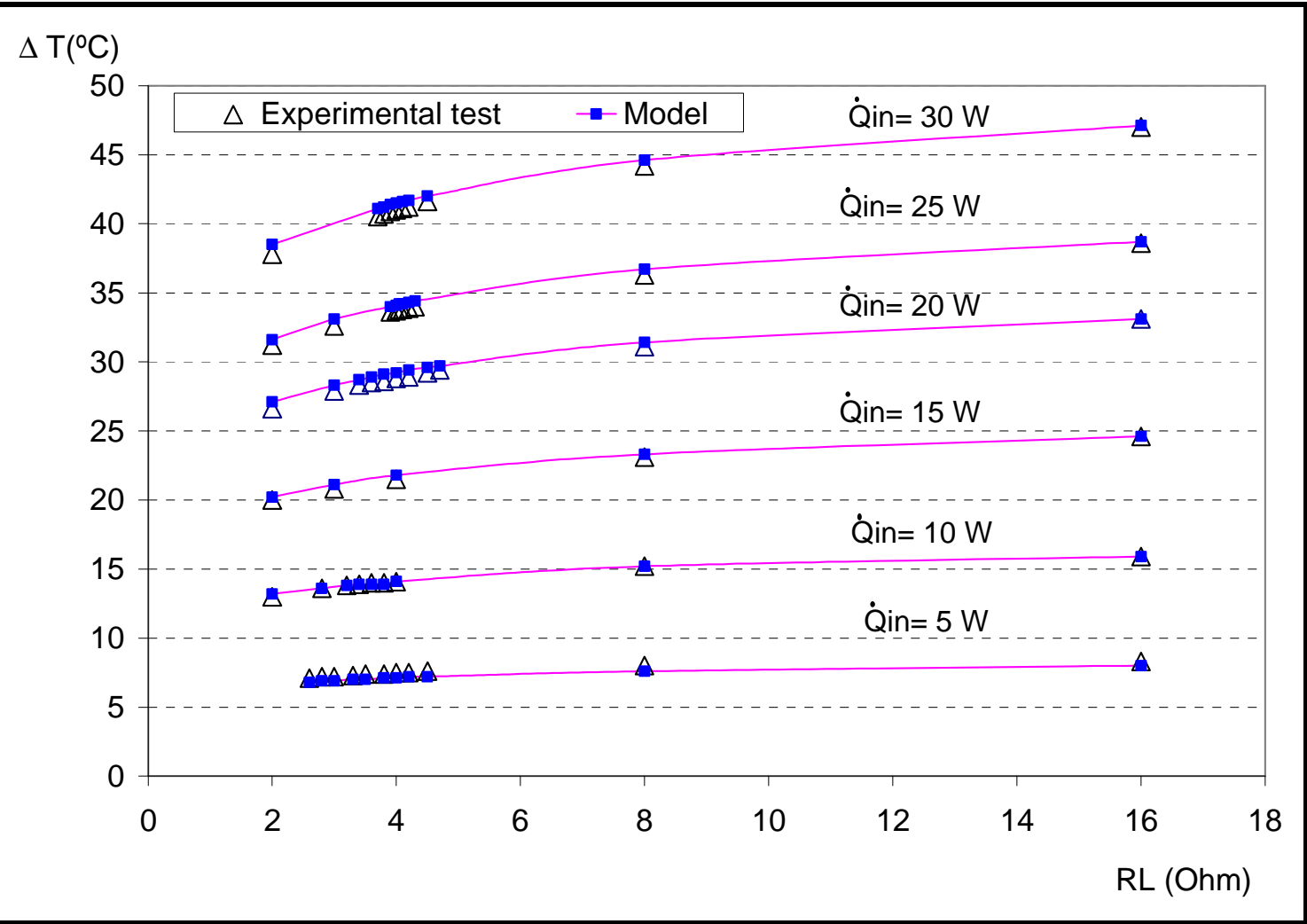

Fig. 6. Temperatura gap between the faces of the Peltier module as a function of the load resistance $\mathrm{R}_{\mathrm{L}}$ for a constant supplied heat flux.

\subsection{Case II: Constant waste heat flux varying the room temperature and the electric load resistance.}

\subsubsection{Output thermoelectric power experimental and simulated}

The tests made for a constant heat flux of $9.97 \mathrm{~W}$ and varying the room temperature from $-25^{\circ} \mathrm{C}$ to $50^{\circ} \mathrm{C}$, Fig. 7 show that the experimental values obtained of generated power vary with the room temperature. This fact is due to the variation of the thermoelectric properties as a function of the temperature. 


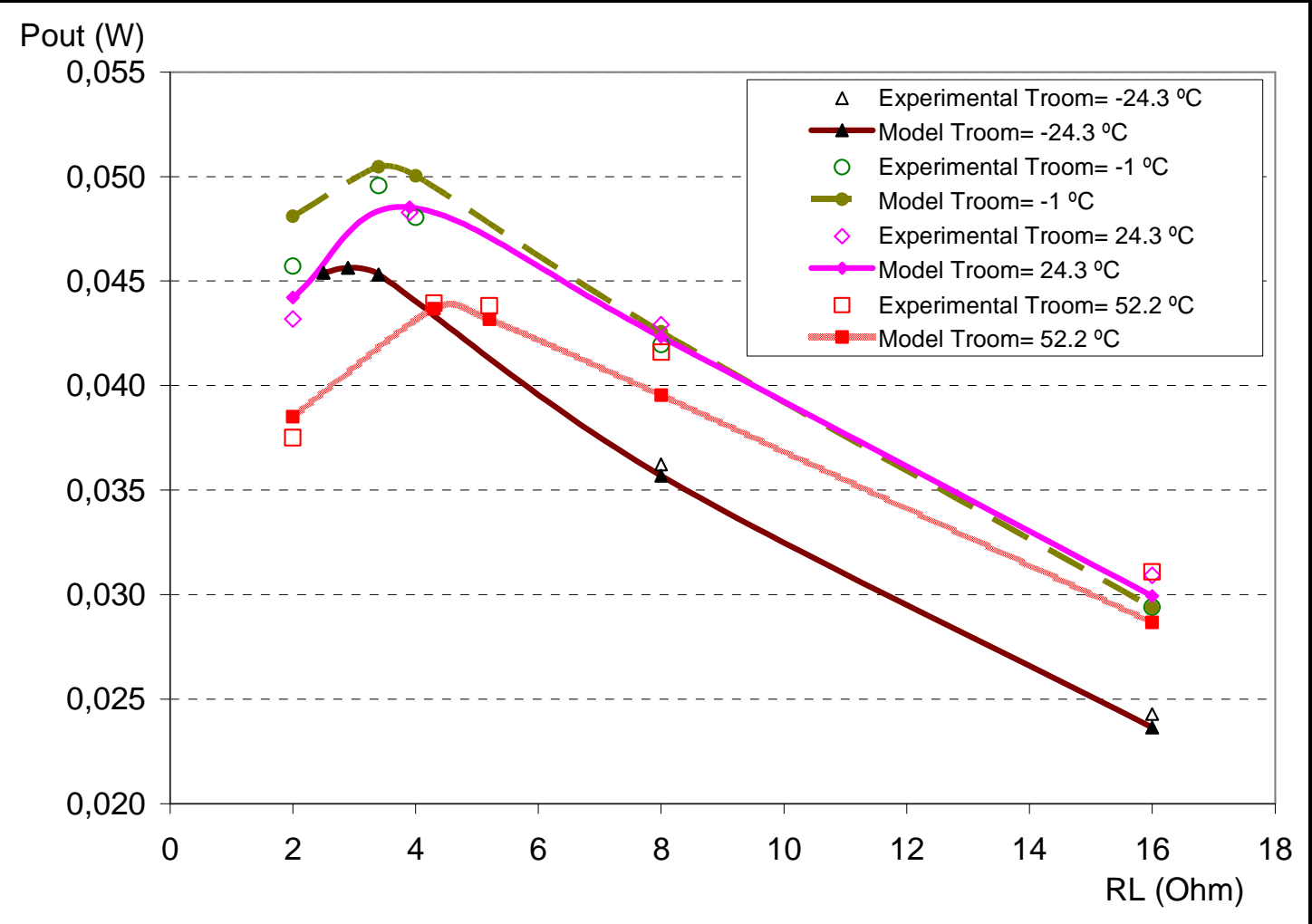

Fig. 7. Thermoelectric generated power for a room temperature constant with a supplied heat flux of $9.97 \mathrm{~W}$.

If we suppose that the thermoelectric properties do not depend on the temperature, for the tests where the heat flux was constant, the value of the electric power generated would be the same, independent of the room temperature. Experimentally we have checked that this supposition is not correct, see Fig.7.

The model and experimental values are shown in Fig. 7, where it can be checked that the errors are lower than the $5 \%$.

In Fig. 8 is shown the maximum power curve (for a constant room temperature, Fig. 7). The maximum of the power curve is produced for a load resistance greater as greater is the room temperature. For this case of study, the curve of maximum power has a parabolic 
shape, reaching the highest value for a room temperature of $-1^{\circ} \mathrm{C}$. The influence of the temperature on the thermoelectric properties depends on the material used, so with other Peltier modules different curves would be gotten.

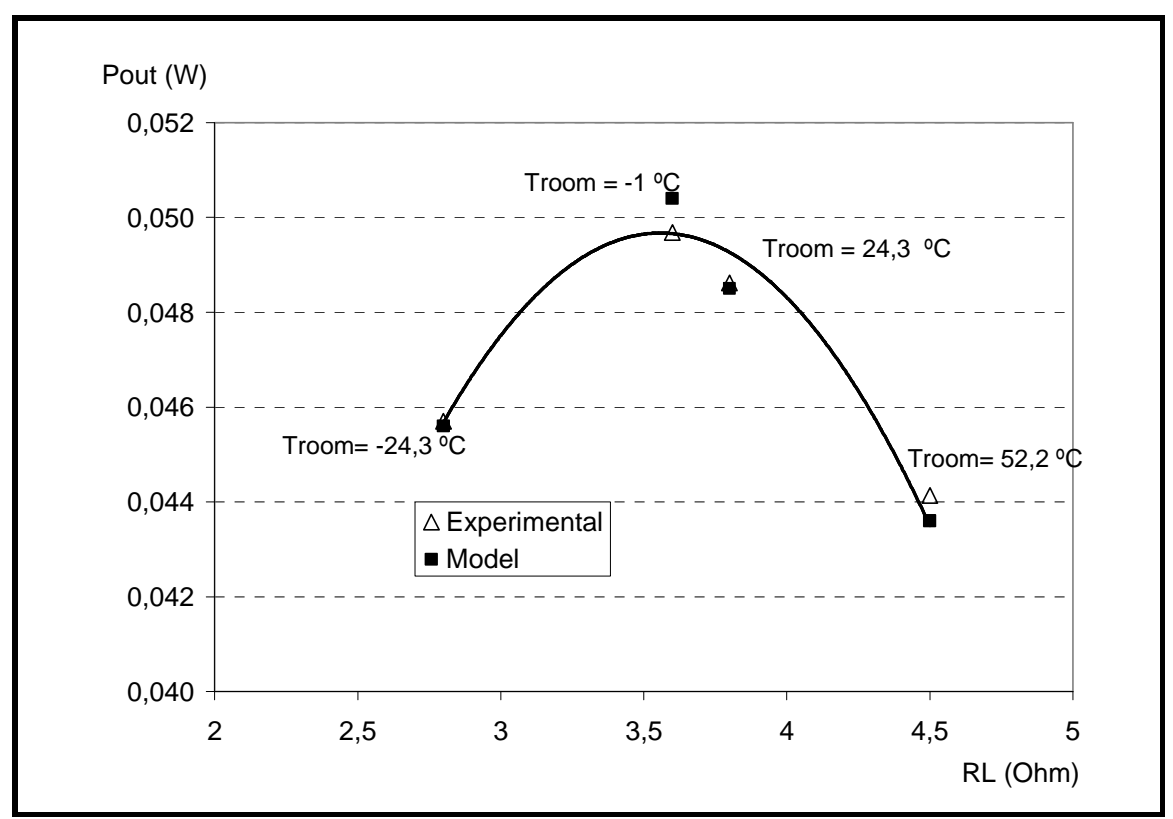

Fig. 8. Maximum power for each curve of constant room temperature, with a supplied heat flux of $9.97 \mathrm{~W}$.

\subsection{Case III: Constant temperature gap between the faces of the Peltier module varying the room temperature and the electric load resistance.}

\subsubsection{Output thermoelectric power experimental and simulated}

In order to check the influence of the room temperature, the cases where the temperature gap between the faces of the Peltier module is constant have been simulated. The electric power generated is shown in Fig. 9, for a constant temperature gap of $20^{\circ} \mathrm{C}$, varying the load resistance. 


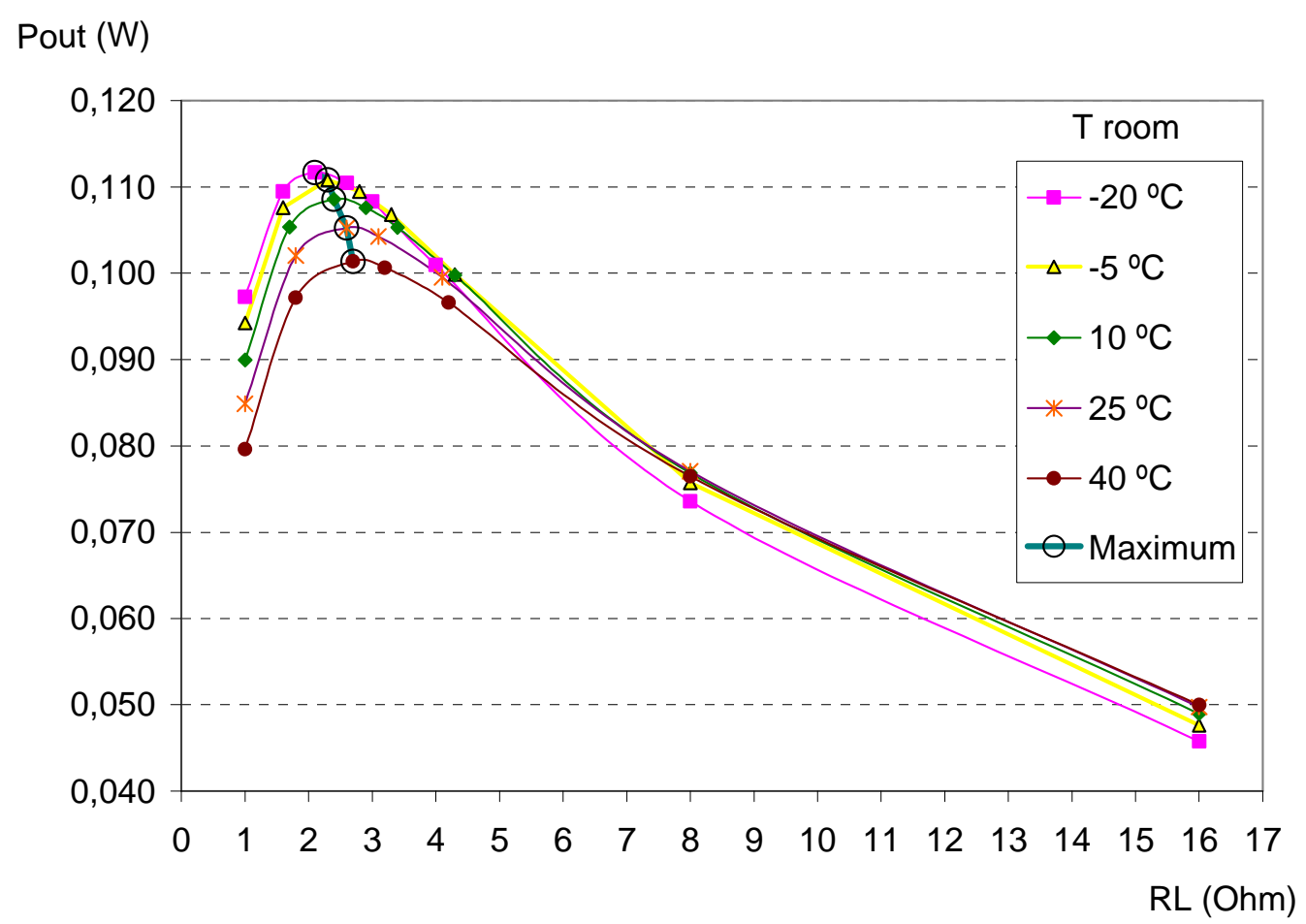

Fig. 9. Thermoelectric generated power for a constant room temperature, with a temperature gap between the faces of the module of $20^{\circ} \mathrm{C}$.

If we suppose that the thermoelectric properties are not a function of the temperature, for the tests where the temperature gap of the faces of the Peltier module is constant the maximum power generated, (calculated using the model of ideal thermocouple or the models that suppose average values for the thermoelectric properties) would be the same independent of the room temperature. However the simulations and the experimental data show that this is not correct.

For the case of our study, Fig. 9, a decrease of the $9 \%$ of the maximum power generated between the lowest room temperature Troom $=-20{ }^{\circ} \mathrm{C}$ and the highest Troom $=40{ }^{\circ} \mathrm{C}$ for a constant temperature gap between the faces of the Peltier module of $20^{\circ} \mathrm{C}$. 
For lower values of load resistance, the generated power is greater as lower is the room temperature. For higher values of room temperature, the generated power is greater as greater is the room temperature, as shown in Fig. 9.

Our simulations allow choosing the load resistance more suitable as a function of the room temperature of operation.

\section{Conclusions}

- A complete computational model has been developed capable to simulate the thermoelectric generation of the Peltier module. It solves the equations of thermoelectricity and the heat transfer phenomenon. The thermoelectric parameters are defined as a function of the temperature, what allow us to keep in mind the Thomson effect.

- The computational model has been validated using experimental data of a test bench for different room temperatures and different heat fluxes. The errors are lower than the $5 \%$.

- Our computational model has important advantages with other calculation methods from the literature such as:

- The model determines the thermoelectric power generated for any boundary conditions of operation (supplied heat flux to the Peltier module and room temperature). It is not necessary to obtain parameters experimentally.

- It solves the system of equations determining the temperatures of all the elements in the thermoelectric system and the heat fluxes involved. It determines 
the transitory state as well as to determine the steady state. This makes the model very useful as a design tool of thermoelectric generation systems.

- The influence of the room temperature, the residual heat flux and the electric load resistance in the behaviour of the thermoelectric generation system was studied.

- It was experimentally proved that demonstrated that the electric load resistance which gives the maximum power varies with the supplied heat flux. Specifically in our case of study, it raises $18 \%$ when the electric load value is increased from $3.3 \Omega(5 \mathrm{~W})$ to $3.9 \Omega(30 \mathrm{~W})$. This effect can be observed in the computational model as well.

- For a constant supplied heat flux it has been verified that the maximum power obtained is a function of the room temperature and the load resistance. For the case of a supplied heat flux of $9.97 \mathrm{~W}$, the curve of the maximum power as a function of the room temperature has a parabolic shape, reaching the maximum at the temperature of $-1^{\circ} \mathrm{C}$.

- For a constant temperature gap between the faces of the Peltier module, the influence of the room temperature in the maximum power was studied. In our case, a decrease of the $9 \%$ of the maximum power generated between the lowest simulated room temperature, $20^{\circ} \mathrm{C}$, and the highest room temperature, $40^{\circ} \mathrm{C}$, has been obtained. 


\section{Bibliography.}

[1] D.K. Benson and T.S. Jayadev, Thermoelectric energy conversion-economical electric power from low grade heat, Proceedings of the Third International Conference on Thermoelectric Energy Conversion, Arlington, TX, IEEE, New York, 12-14, (1980), p. $27-56$.

[2] D.M. Rowe, CRC Handbook of Thermoelectrics. ISBN 0-83-0146-7 (1995), pp $19-25$.

[3] A. F. Ioffe, "Semiconductor Thermoelements and Thermoelectric Cooling", Infosearch Ltd., London 1957.

[4] H.J. Goldsmid, "Conversion Efficiency and Figure-of-Merit”, in CRC Handbook of Thermoelectrics, D.M. Rowe, Editor. 1995, CRC Press: New York, USA, pp.19-25.

[5] G.S. Nolas, J. Sharp, and H.J. Goldsmid, "Historical Development", in Thermoelectrics. Basic Principles and New Materials Developments. 2001, Springer: Australia, pp.1-13

[6] D.M. Rowe, G. Min, Evaluation of thermoelectric modules for power generation, Journal of Power Sources, 73, (1998), pp. 193-198.

[7] D.M. Rowe, G. Min, Design theory of thermoelectric modules for electrical power generation, IEE Proc. Sci. Meas Technology Vol 143 No 6, (1996), pp. 351-356 ISSN $1350-2344$

[8] S.A. Omer, D.G. Infield, Design optimization of thermoelectrics devices for solar power generation, Solar energy materials \& solar cells, 53, (1998), pp. 67-82 
[9] D.M. Rowe, G. Min, Optimisation of thermoelectric module geometry for 'waste heat' electric power generation, Journal of Power Sources, 38, (1992), pp. 253-259

[10] C. Wu, Analysis of waste-heat thermoelectric power generators, Applied Thermal Engineering 16, (1996), pp.63-69.

[11] R. Nuwayhid et al. On entropy generation in thermoelectric devices, Energy Conversion and Management. 41, (2000), pp. 891-914.

[12] A. Arenas, Tesis Doctoral: "Determinación de Nuevos Criterios que Permitan la Optimización de Parámetros de Diseño de una Bomba de Calor por Efecto Peltier", Departamento de Fluidos y Calor. Universidad Pontificia Comillas, (Madrid, 1999)

[13] G. Yu, and L. Chen, "Theoretical Revision on DT-I Formula for A.F. Ioeffe's Thermoelectric Cooling”. Proc. $11^{\text {th }}$ International Conference on Thermoelectrics., Arlington, Texas, USA., (1992), pp. 282-284.

[14] P.G. Lau, and R.J. Buist, "Temperature and Time Dependant Finite-Element Model of a Thermoelectric Couple". Proc. 15th International Conference on Thermoelectrics. 1996, pp. 227-233.

[15] P.G. Lau, and R.J. Buist, "Calculation of Thermoelectric Power generation Performance Using Finite Element Analysis". Proc. $16^{\text {th }}$ International Conference on Thermoelctrics, 1997 pp. 563-566

[16] J. G. Stockholm, and D. W. Stockholm, "Thermoelectric Modelling of a Cooling Module with Heat Exchangers". Proc. $12^{\text {th }}$ International Conference on Thermoelctrics, 1992, pp. 140-146. 
[17] D. Kondratiev, and L. Yershova, "TE Coolers Computer Simulation: Incremental Upgrading of Rate Equations Approch". Proc. $6^{\text {th }}$ European Workshop on Thermoelectrics. 2001, Freiburg, Germany, pp. 204-211.

[18] D. Astrain, J.G. Vián, J. Albizua, Computational model for refrigerators based on Peltier effect application, Applied Thermal Engineering, (2005), pp 3149-3162

[19] J. G Vián, D. Astrain, J.J. Aguas. Thermoelectric equipment to keep laboratory test-tube at a controlled temperature, Journal of Thermoelectricity, n³ (1999), pp 52-65.

[20] J.G. Vián, D. Astrain, and M. Dominguez, , Numerical modelling and design of a thermoelectric dehumidifier. Applied Thermal Engineering, (2002), pp. 407-422.

[21] T.M. Ritzer, P.G. Lau, Economic Optimization of Heat Sink Design, 13th International Conference on Thermoelectrics, Kansas City, MO, (1994), pp. 77-100. 